\title{
DISTINÇÃO ENTRE TEXTURA SPINIFEX E ARRANJOS DE OLIVINA METAMÓRFICA
}

\author{
LÉO AFRANEO HARTMANN*, MARCUS V. REMUS* e JAIR C. KOPPE*
}

\begin{abstract}
Elongated blades of olivine in a talc-carbonate (or sulphide) matrix are formed by metamorphic processes from serpentinites, and have been misidentified as igneous spinifex textures. The two types may be distinguished texturally and chemically. Metamorphic olivines show straight borders and the crystals overlap in poiquiloblastic habit, whereas volcanic olivines are often skeletal and crystals do not overlap. Whenever crystals are not entirely serpentinized, those of metamorphic origin will show negative elongation, and igneous crystals will show positive elongation. Fo content is strongly controlled by the $\mathrm{Fe} / \mathrm{Mg}$ ratio of the rock. Samples with elongated metamorphic olivines in a talc matrix contain approximately $40-43 \% \mathrm{MgO}$, as opposed to spinifex textured igneous samples which show less than $33 \% \mathrm{MgO} \mathrm{TiO}_{2}$ is much lower in olivine-talc metamorphic rocks.
\end{abstract}

\begin{abstract}
INTRODUÇÃO Lavas komatiíticas foram identificadas por Viljoen \& Viljoen (1969) no Greenstone Belt de Barberton e são comuns em seqüências vulcano-sedimentares arqueanas (Nesbitt \& Sun 1976, Arndt \& Nisbet 1982), mas são extremamente raras em associações pós-arqueanas. As texturas encontradas nessas rochas (textura spinifex de Nesbitt 1971) estão bem documentadas na bibliografia (Donaldson 1982), até no Brasil (Teixeira et al. 1981, Jahn \& Schrank 1983). Da mesma forma, são bem conhecidas as texturas associadas com o crescimento de olivina durante o metamorfismo progressivo de serpentinitos (Oliver et al. 1972, Evans \& Trommsdorf 1974, Collerson et al. 1976, Snoke \& Calk 1978), até no Brasil (Hartmann 1982, Pimentel \& Fuck 1986). As olivinas metamórficas apresentam dois tipos principais de morfologia. Um tipo é porfiroblástico, ocorrendo em paragênese com tremolita e clorita, e o outro é tabular, em paragênese com talco e carbonato (ou sulfeto). Este segundo tipo pode ser confundido com a textura spinifex (Cesar \& Soliani 1984, Moreira \& Marimom 1984, Flinn \& Moffat 1985) e é objeto do presente trabalho.
\end{abstract}

\section{CRITÉRIOS DE DISTINÇÃO Critérios de campo e pe-} trográficos As olivinas vulcânicas tendem a ser preservadas somente em terrenos de baixo grau de metamorfismo, raramente ultrapassando o fácies xistos verdes médio (zona da biotita). Complexos vulcânicos polideformados apresentam baixa probabilidade de preservação da olivina vulcânica.

Olivinas de cristalização metamórfica podem formar-se em serpentinitos típicos a partir da isógrada da biotita, vindo a ocorrer em paragênese com talco. Conforme mostra Turner (1981, p. 173), a faixa composicional de rochas ultramáficas e a faixa de temperatura de ocorrência da paragênese olivina + talco são muito amplas e permitem prever que essa associação mineralógica seja amplamente difundida na natureza. Em terrenos de fácies xistos verdes superior (zona da granada) e fácies anfibolito inferior (zona da estaurolita), é mais provável que um cristal de olivina de xisto magnesiano seja de origem metamórfica do que de derrame komatítico. O metamorfismo de contato pode igualmente gerar placas de olivina em matriz de talco (Matthes 1971, Hietanen 1977, Naumann \& Hartmann 1984).

As características de campo são distintivas, na maioria dos casos, entre um derrame (zoneamento vertical, disjunção poliedral) e uma lente metamórfica. Esta última não apresenta zoneamento vertical da textura nem disjunção poliedral; a olivina metamórfica, que pode apresentar tamanho de milímetros até $1 \mathrm{~m}$, apresenta, no caso de cristalização sintectônica a uma deformação regional, grosseiro paralelismo com a xistosidade das rochas encaixantes.

Do ponto de vista petrográfico, as olivinas metamórficas só são alongadas quando em paragênese com talco e magnesita (ou sulfeto). Conforme salientam Evans \& Trommsdorf (op. cit., p. 132), “(...) a olivina em outras paragêneses metamórficas (por exemplo, em associação com enstatita + clorita, antofilita ou cummingtonita + clorita, antigorita + clorita) e a olivina em talco-olivina xistos tende a ser granoblástica, e comumente muito grosseira". Afirmam os mesmos autores que "veios de substituição pós-cinemáticos também podem conter a paragênese talco + olivina + magnesita, sendo que nestes casos foram observados cristais aciculares de olivina com mais de $1 \mathrm{~m}$ de comprimento". Os cristais metamórficos de olivina apresentam bordos retos e podem estar intercrescidos poiquiloblasticamente, não se apresentando esqueletiformes, que é uma feição típica de olivinas em textura spinifex. O comprimento dos cristais situa-se invariavelmente ao longo do eixo $b$, conferindo-lhes sinal negativo de elongação, ao passo que os cristais de origem vulcânica são alongados ao longo do eixo $c$, com sinal de elongação positivo (Evans \& Trommsdorf op. cit., p. 132). Algumas das feições referidas estão ilustradas nas fotos $1,2,3,4$ e 5 .

Critérios químicos A composição química das olivinas metamórficas depende de diversos fatores, como a composição da rocha, a natureza e volume das fases coexistentes, e do estado de oxidação do ferro. Para um certo conteúdo de Fo, no entanto, o teor de Ni é mais baixo (Evans \& Trommsdorf 1974). O teor de $\mathrm{CaO}$, no entanto, é extremamente baixo, quando comparado com olivinas vulcânicas. Como se observa na tabela 1 , tanto o $\mathrm{CaO}$ quanto $\mathrm{o} \mathrm{Cr}_{2} \mathrm{O}_{3}$ são extremamente baixos nas análises 1 a 6 , que representam olivinas metamórficas, quando comparados com as análises 7 a 10 de olivinas vulcânicas. Os cristais de olivina das amostras correspondentes às análises 1 e 2 têm sinal de elongação negativo.

A composição química da rocha pode ser elucidativa em relação a sua natureza ígnea ou metamórfica, quando comparadas amostras com textura spinifex e jackstraw. Cabe lembrar que é comumente aceito que a textura spinifex denota a ocorrência de líquidos silicatados com elevado teor de magnésio, ou seja, derrames de lava ultramáfica. Conforme amplamente apresentado em Arndt \& Nisbet (1982) e destacado por Nesbitt \& Hartmann (1986), o extremo máximo de magnésio em amostras com textura spinifex é de 32\%-33\% MgO, em base anidra. Em contraste, amostras com placas de olivina metamórfica associadas a talco contêm $40 \%-44 \% \mathrm{MgO}$ (Tab. 2). O último teor de magnésio é semelhante à própria composição estimada do manto (Sun \& Nesbitt 1977), o que exigiria 
Tabela 1 - Análises químicas comparativas entre olivinas metamórficas (1 a 6) e vulcânicas (7 a 10): 1 - olivina de artofilita-olivina-talco xisto do Complexo Cambaizinho (RS), amostra MR-990; 2 - olivina de talco-tremolita-olivina xisto do Complexo Cambaizinho (RS), amostra MR-101; 3 - olivina de talco-olivina-tremolita xisto do Labrador, Canadá (Collerson et al. 1976, p. 448, coluna C); 4 - olivina de tremolita harzburgito metamórfico do Cerro da Mantiqueira (RS), amostra CM-3; 5 - olivina de clorita-cummingtonita-tremolita-enstatita-olivina xisto (Rice et al. 1974, Tab. 3, amostra 31A); 6 - olivina de hornblenda lherzólito do Complexo Granulítico Santa Maria Chico (RS) (média de seis análises), amostra CGSMC-38; 7 - olivina de komatíto com textura spinifex (média de 15 análises da zona A1 de Arndt et al. 1977, Tab. 2); 8-olivina de komatíto (Bickle 1982, p. 487, amostra 49J); 9 - olivina de komatíto (Bickle 1982, p. 487, amostra NG7639); 10 - olivina de komatíto (Smith \& Erlank 1982, p. 351, amostra HSS-8). Análises 1, 2, 4 e 6, pelo autor. (-não analisado)

\begin{tabular}{l|c|c|c|c|c|c|c|c|c|c}
\hline \multicolumn{1}{c|}{ Amostra } & \multicolumn{1}{c|}{} & $\mathbf{2}$ & $\mathbf{3}$ & $\mathbf{4}$ & $\mathbf{5}$ & $\mathbf{6}$ & $\mathbf{7}$ & $\mathbf{8}$ & $\mathbf{9}$ & $\mathbf{1 0}$ \\
\hline $\mathrm{SiO}_{2}$ & 42,02 & 40,58 & 39,19 & 41,14 & 40,8 & 39,98 & 39,4 & 41,4 & 41,1 & 40,00 \\
$\mathrm{TiO}_{2}$ & 0,02 & 0,02 & 0,02 & 0,02 & - & 0,02 & - & - & - & 0,00 \\
$\mathrm{Al}_{2} \mathrm{O}_{3}$ & - & - & 0,02 & - & 0,02 & 0,00 & - & 0,00 & 0,05 & 0,05 \\
$\mathrm{Cr}_{2} \mathrm{O}_{3}$ & 0,02 & - & 0,02 & 0,00 & - & 0,00 & 0,19 & 0,18 & 0,18 & 0,12 \\
$\mathrm{FeO}$ & 14,03 & 13,41 & 18,09 & 10,70 & 8,85 & 14,45 & 8,8 & 6,27 & 10,32 & 11,02 \\
$\mathrm{NiO}$ & 0,23 & 0,30 & 0,52 & 0,41 & 0,40 & 0,24 & 0,46 & 0,51 & 0,26 & 0,367 \\
$\mathrm{MnO}$ & 0,11 & 0,14 & 0,24 & 0,12 & 0,18 & 0,22 & - & - & - & 0,15 \\
$\mathrm{MgO}$ & 43,06 & 45,58 & 42,24 & 48,64 & 49,5 & 45,41 & 51,0 & 51,61 & 49,49 & 47,73 \\
$\mathrm{CaO}$ & 0,03 & 0,03 & 0,00 & 0,03 & 0,01 & 0,03 & 0,20 & 0,19 & 0,23 & 0,31 \\
\hline Total & 101,06 & 100,06 & 100,34 & 101,06 & 99,74 & 100,45 & 100,1 & 100,16 & 101,63 & 99,75 \\
\hline
\end{tabular}

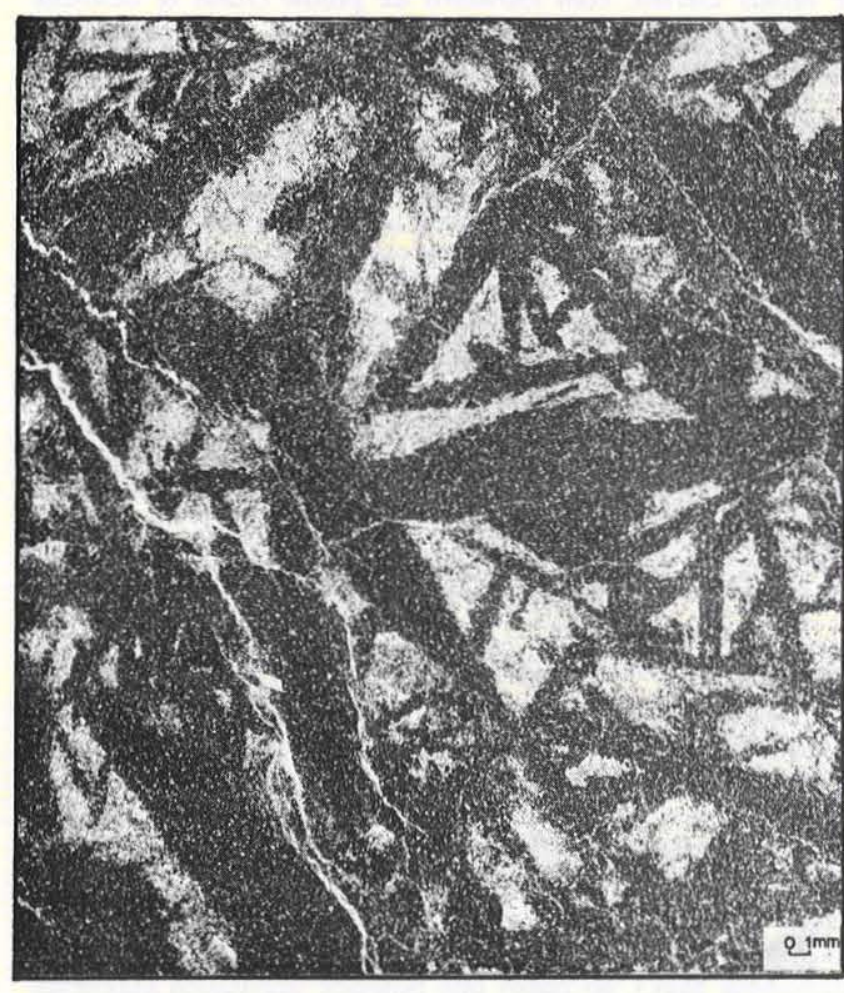

Foto 1 - Placas pretas de olivina (agora serpentina), em matriz de talco, em arranjo metamórfico da textura jackstraw. Amostra DJK-03 do Complexo Bossoroca, RS

a fusão total de uma fração do manto para a obtenção de um líquido com essa composiçāo, hipótese muito pouco provável. É bem mais provável que rochas com teor tão elevado de $\mathrm{MgO}$ correspondam a cumulatos ou a resíduos de lixiviação metassomática durante a serpentinização original. Em terrenos mais jovens, podem corresponder a fraçōes do manto carreadas até a crosta continental em ofiólitos. $\mathrm{O}$ teor de $\mathrm{TiO}_{2}$ da parte líquida de derrames komatiíticos situa-se acima de $0,4 \%$,

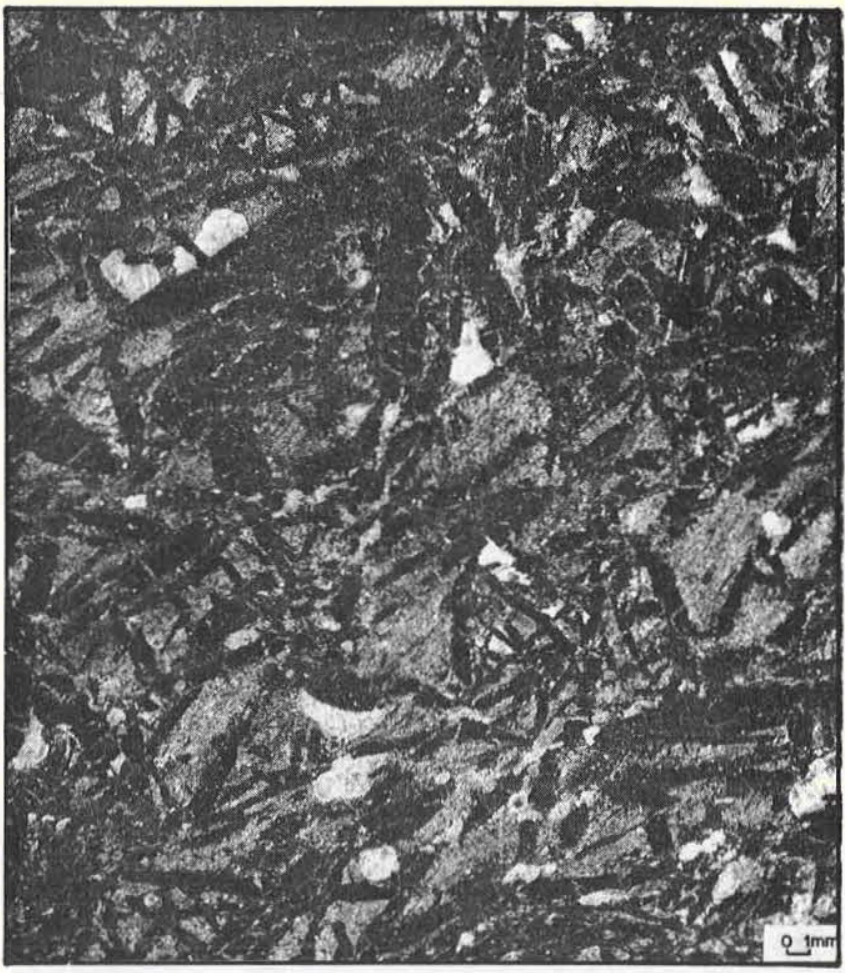

Foto 2 - Placas pretas de olivina (inteiramente serpentinizada) em matriz de talco. $O$ carbonato acessório mostra relações de equilíbrio com a olivina. A textura é metamórfica jackstraw. Amostra DJK-04 do Complexo Bossoroca, RS

ao passo que os metamorfitos a olivina + talco contêm teor muito mais baixo, da ordem de $0,05 \%$. Os komatítos contêm razão $\mathrm{CaO} / \mathrm{Al}_{2} \mathrm{O}_{3}$ igual ou inferior a 1,5 ao passo que os metamorfitos têm razão variada mas em muitos casos muito superior.

As análises químicas comparativas de rochas ultramáficas da tabela 2 correspondem a amostras com textura metamórfica jackstraw (análises 1 e 2) e textura vulcânica spinifex (aná- 


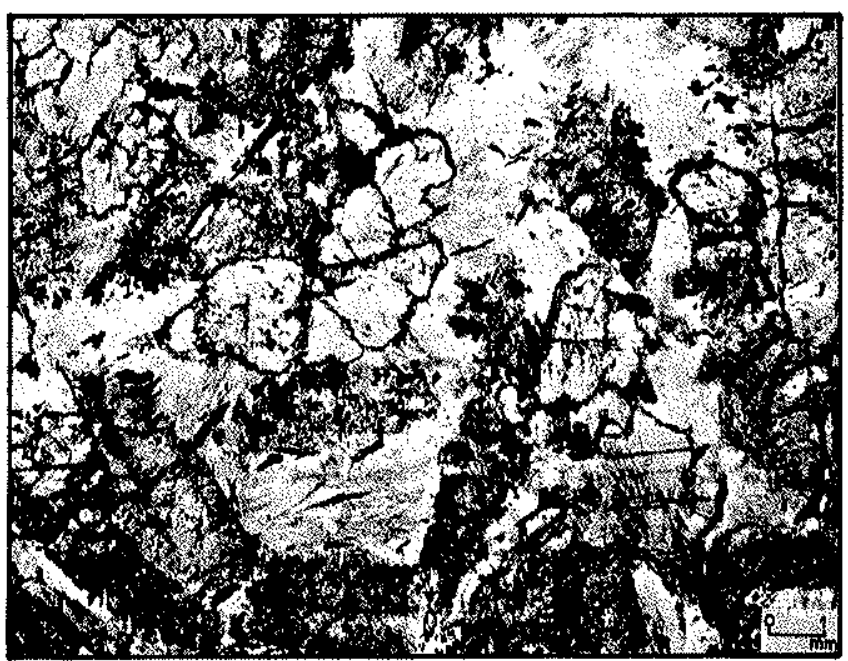

Foto 3 - Observação microscópica, em luz natural, de textura jackstraw, com destaque para os cristais de carbonato em equilibrio textural com a olivina, pois não a recortam. As porçöes mais claras são de talco e as mais escuras, de olivina serpentinizada; o carbonato tem relevo alto e contornos nítidos. Amostra DJK-04 do Complexo Bossoroca, RS

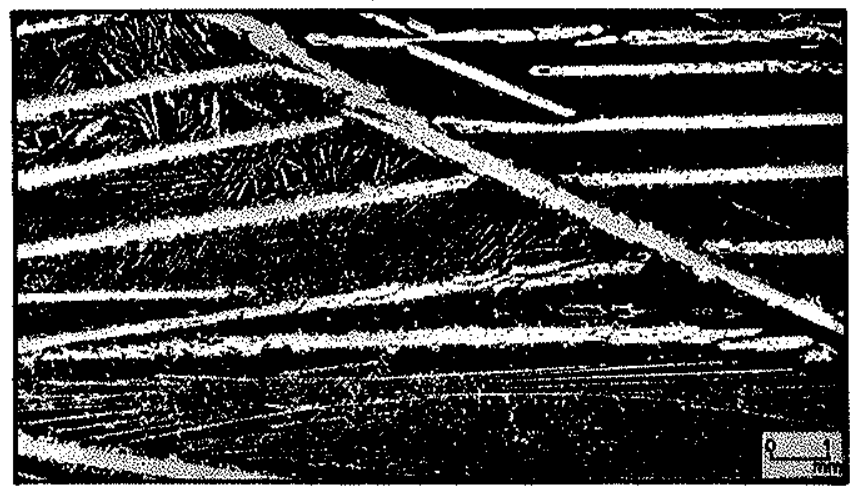

Foto 4 - Komatitío com textura spinifex da Austrália. Áreas claras são de olivina serpentinizada e areas escuras intersticiais, clorita-tremolita. Foto cedida por Nesbitt, R.W.

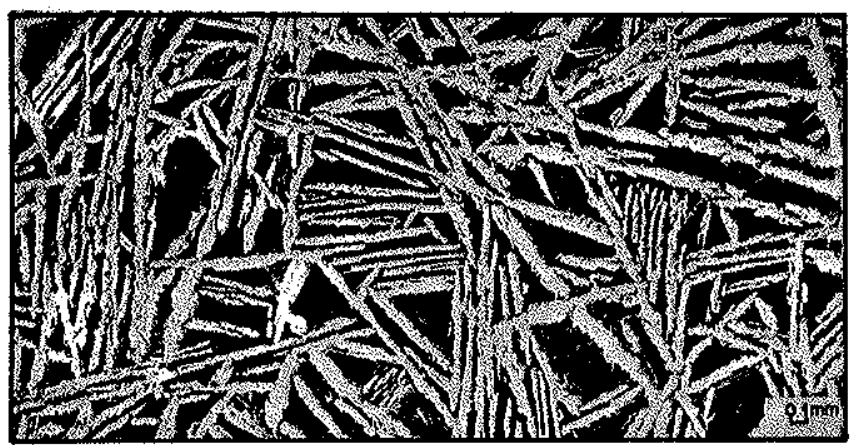

Foto 5 - Komatifto com textura spinifex da Austrália. Áreas claras são de olivina serpentinizada e areas escuras, cloritatremolita. Foto cedida por Nesbitt, R.W. lises 3, 4 e 5). A análise 1 é um exemplo dos Estados Unidos, ao passo que a análise 2 corresponde a uma ocorrência do Rio Grande do Sul, do Complexo Bossoroca. Esta análise 2 é referida por Moreira \& Marimon (1984) e Cesar \& Soliani (1984) como sendo correspondente a uma amostra de komatiito com textura spinifex. No entanto, a foto publicada pelos dois últimos autores é muito semelhante à textura jackstraw e a paragênese olivina + talco é a mesma. Constata-se, da mesma forma, que a análise 2 é de uma rocha ultramáfica com $44,28 \% \mathrm{MgO}$; este teor situa-se muito acima da composição dos líquidos ultramáficos reconhecidos em outras regiōes. A composição química dessa amostra está muito próxima à de um serpentinito, devendo tratar-se de um metasserpentinito de fácies anfibolito inferior. O grau de metamorfismo do Complexo Cambaizinho é anfibolito inferior, conforme indicam as rochas associadas, como anfibolitos a hornblenda e plagioclásio.

Tabela 2 - Analises químicas comparativas de rochas ultramáficas: 1 - talco-olivina ultramáfico (textura jackstraw dos Montes Klamath, EUA. Snoke \& Calk 1978): 2 - serpentinito com clorita, amostra 963/278 (média de A, B, C de Moreira \& Marimon 1984); 3 - komatitto com textura spinifex, Yackadindie, Austrália (Nessitt \& Sun 1976); 4 - komatito com textura spinifex, Munro, Canada (Nesbitt \& Sun 1976); 5 - komatiito de Minas Gerais, com estrutura de pillow (Jahn \& Schrank 1983 p. 9, amostra A24H). As análises são fornecidas $100 \%$ anidro e ferro total como $\mathrm{Fe}_{2} \mathrm{O}_{3}$

\begin{tabular}{l|r|r|r|r|r}
\hline Amostra & \multicolumn{1}{|c|}{$\mathbf{1}$} & \multicolumn{1}{|c|}{$\mathbf{2}$} & \multicolumn{1}{c|}{3} & \multicolumn{1}{c|}{$\mathbf{4}$} & \multicolumn{1}{c}{5} \\
\hline $\mathrm{SiO}_{2}$ & 48,40 & 44,28 & 44,43 & 45,60 & 49,43 \\
$\mathrm{TiO}_{2}$ & 0,02 & 0,07 & 0,28 & 0,44 & 0,33 \\
$\mathrm{Al}_{2} \mathrm{O}_{3}$ & 1,30 & 0,52 & 5,36 & 9,52 & 6,91 \\
$\mathrm{Fe}_{2} \mathrm{O}_{3}$ & 8,00 & 9,90 & 12,53 & 12,73 & 9,93 \\
$\mathrm{MnO}$ & 0,07 & 0,10 & 0,22 & 0,23 & 0,21 \\
$\mathrm{MgO}$ & 41,40 & 44,28 & 31,72 & 20,67 & 25,84 \\
$\mathrm{CaO}$ & 0,78 & 0,10 & 4,87 & 10,87 & 6,90 \\
$\mathrm{Na} \mathrm{O}_{2} \mathrm{O}$ & 0,00 & 0,60 & 0,32 & 0,55 & 0,29 \\
$\mathrm{~K}_{2} \mathrm{O}$ & 0,00 & 0,10 & 0,00 & 0,04 & 0,05 \\
$\mathrm{NiO}$ & 0,21 & 0,02 & 0,21 & 0,09 & 0,15 \\
$\mathrm{Cr}_{2} \mathrm{O}_{3}$ & 0,29 & 0,23 & 0,45 & 0,48 & 0,25 \\
\hline
\end{tabular}

CONCLUSÃo A textura de placas alongadas de olivina associadas a talco e carbonato (ou sulfeto) é designada de jackstraw por Snoke \& Calk (1978). Sua origem está ligada à recristalização no estado sólido de olivina e demais minerais, tendo a olivina um campo de estabilidade a partir da isógrada da biotita em serpentinitos comuns e a partir da is 6 grada da estaurolita em serpentinitos a talco, que são mais silicosos. Os cristais de olivina não são esqueletiformes, em distinção com a textura spinifex. Amostras com textura jackstraw contêm $40 \%-44 \% \mathrm{MgO}$, ao passo que líquidos silicatados magnesianos com textura spinifex não ultrapassam $33 \% \mathrm{MgO}$, em base anidra. Detalhadas observações de campo, petrográficas e químicas, permitem distinguir os dois tipos de olivina.

Agradecimentos $O$ primeiro autor é pesquisador do Conselho Nacional do Desenvolvimento Científico e Tecnologico, que tem fornecido apoio financeiro para diversos projetos, em particular para pesquisas de pós-doutorado na Universidade de Southampton, Inglaterra, através do proc. $\mathrm{n}^{\mathbf{9}}$ 20.2453/83-GC, em 1985. Durante a estada no exterior, dis" cussōes com R.W. Nesbitt foram muito proveitosas em torno do tema do presente artigo. 


\section{REFERÊNCIAS BIBLIOGRÁFICAS}

ARNDT, N.T; NALDRETT, A J ; PYKE, D R, - 1977 - Komatiitic and iron-rich tholeiitic lavas of Munro Township, northeast Ontario. J. Petrol., 18:319-369.

ARNDT, N.T, \& NISBET, E. (eds.) -- 1982 - Komatiites. Londres, Allen \& Unwin, $526 \mathrm{p}$.

BICKLE, M.J. - 1982 - Komatiites in the Pilbara Block, Western Australia. In: ARNDT, N.T, \& NISBET, E.G. eds. Komatïtes Londres, Allen \& Unwin, p. 105-115

CÉSAR, A.R S.F, \& SOLIANI, E - 1984 - Compartimentação tectônica do Cráton do Rio de la Plata. In: CONGR. BRAS. GEOL., 33, Rio de Janeiro, 1984. Anais... Rio de Janeiro, SBG. v. 5, p. 2426.2434 .

COLLERSON, K.D.; JESSEAU, C.W.; BRIDGWATER, D. - 1976Contrasting types of bladed olivine in ultramafic rocks from the Archaen of Labrador. Can. J. Earth Sci., 13:442-450.

DONALDSON, C.H. - 1982 - Spinifex-textured komatiites: a review of textures, minerals, compositions, and layering. In: ARNDT, N.T. \& NISBET, E.G. eds. Komatiites, Londres, Allen \& Unwin, p. 213-244.

EVANS, B.W. \& TROMMSDORF, V. - 1974-On elongate olivine of metamorphic origin. Geology, 2:131-132.

FLINN, D. \& MOFFAT, D.T. - 1985 - A peridotitic komatiite from the Dalradian of Shetland. Geol. Jour.; 20:287-292.

HARTMANN, L.A. - 1982 - Textura metamórfica de olivina em talcoserpentinitos da região de Mata Grande (RS). Acta Geol. Leop., $12: 179-188$

HIETANEN, A - 1977 - Blades of olivine in ultramafic rocks from Northern Sierra Nevada; California. Jour. Res. U.S.G.S., 5(2):217-219.

JAHN, B.M. \& SCHRANK, A. - 1983-REE geochemistry of komatiites and associated rocks from Piumhi, Southeastern Brazil. Prec. Res., 21:1-20.

MATTHES, S. - 1971 - Die ultramafischen Hornfelse, insbesondere ihre Phsenpetrologie. Fortsch. Mineral., 48(1):109-127.

MOREIRA, M.L.O.\& MARIMON, M.P.C. - 1984 -.-Textura spinifex em rochas komatiíticas pertencentes ao Complexo Vacacaí, RS. In: CONGR. BRAS. GEOL., 33, Rio de Janeiro, 1984. Anais. Rio de Janeiro, SBG. v. 5, 2599-2606.

NAUMANN, M.P. \& HARTMANN, L.A. - 1984 - Cornubianitos ultramáficos e metassomatitos associados da regiăo do Arroio Corticeira, Ibaré, RS, In: CONGR. BRAS, GEOL., 33, Rio de Janeiro, 1984. Anais... Rio de Janeiro, SBG. v. 8, p. 4279-4290;

NESBITT, R.W. - 1971 - Skeletal crystal forms in the ultramafic rocks of the Yilgarn Block; evidence for an Archaean ultramafic liquid. Geol. Soc. Austr. Spec. Publ., 3:331-348.
NESBITT, R.W. \& HARTMANN, L.A. - 1986 - Comments on 'A peridotitic komatiite from the Dalradian of Shetland' by Flinn, $D$. and D.T. Moffat. Geol. Jour., 21:201-205.

NESBITT, R.W. \& SUN, S.S. - 1976 - Geochemistry of Archean spinifex-textured peridotites and magnesian and low-magnesian tholeiites. Earth-Planet. Sci. Lett., 31:433-453.

OLIVER, R.L.; NESBITT, R.W.; HANSEN, D.M.; FRANZEN, N. 1972 - Metamorphic olivine in ultramafic rocks from Western Australia. Contrib. Mineral Petrol, 36:335-342.

PIMENTEL, M.A. \& FUCK, R.A. - 1986 - Geologia da Seqüência Vulcano-sedimentar de Arenópolis (GO), Rev. Bras. Geoc., 16(2):217-223.

RICE, J.M.; EVANS, B.W.; TROMMSDORF, V. - 1974 - Widespread occurence of magnesiocummingtonite in ultramafic schists, Cima di Gagnone, Ticino, Switzerland. Contrib. Mineral. Petrol., di Gagnone,

SABÓIA, L.A. \& TEIXEIRA, N.A. - 1980 - Lavas ultrabásicas da unidade basal do "greenstone belt" de Crixás (GO): uma nova classe de rochas ultrabásicas no estado de Goiás. Rev. Bras. Geoc. 10(1): $28-42$

SMITH, H.S. \& ERLANK, A.J. - 1982 - Geochemistry and petrogenesis of komatiites from the Barberton greenstone belt, South Africa. In: ARNDT, N.T. \& NISBET, E.G. (eds.) Komatites, Londres, Allen \& Unwin, p. 347-397.

SNOKE, A.W. \& CALK, L.C. - 1978 - Jackstraw-textured talc-olivine rocks, Preston Peak area, Klamath Mountains, California. Geol. Soc. Am. Bull., 89:223-230.

SUN, S.-S. \& NESBITT, R.W.--1977-Chemical heterogeneity of the Archaean mantle, composition of the earth and mantle evolution. Earth and Planet. Sci.Lett., 35:429-448.

TEIXEIRA, N.A.; SABÓIA, L.A.; FERREIRA, M.C.B.; TEIXEIRA, A.S.; CASTRO, J.H.G. - 1981 - Estruturas e texturas das lavas ultramáficas do "greenstone belt" de Crixás, Goiás, Brasil. Goiânia, SBG/NCO. Bol.Inform. 10:33-87.

TURNER, F.J, - 1981 - Metamorphic petrology; mineralogical, field, and tectonic aspects. New York, McGraw-Hill, $524 \mathrm{p}$.

VILJOEN, M.J. \& VILJOEN, R.P. - 1969 - The geology and geochemistry of the lower ultramafic unit of the Onverwacht Group and a proposed new class of igneous rocks. Geol. Soc. S. Afr. Spec. Publ., 2:55-86.

MANUSCRITO 416 Recebido em 09 de fevereiro de 1987 Revisão aceita em 15 de setembro de 1987

A formulação de um problema é, muitas vezes, mais importante que sua resolução, a qual depende simplesmente de uma habilidade matemática ou experimental. Fazer novas perguntas e considerar novas possibilidades para enfocar velhos problemas através de um novo ângulo, exige imaginação criadora e indica o verdadeiro progresso da ciência. 